\title{
PENERAPAN AUGMENTED REALITY PADA BROSUR YAMAHA TJAHAJA BARU UNTUK PROMOSI BERBASIS ANDROID (Studi Kasus Di Yamaha Tjahaja Baru)
}

\author{
Febri Hadi, Randy Permana, Satria Yulanda \\ Universitas Putra Indonesia YPTK Padang \\ e-mail: febri_hadi@upiyptk.ac.id
}

\begin{abstract}
Abstrak
Augmented Reality (AR) adalah sebuah teknologi yang mampu memproyeksikan objek virtual 3D ke dalam lingkungan nyata sehingga objek 3D tersebut dapat berinteraksi secara realtime. Tujuan dari penelitian ini adalah untuk mengembangkan media baru dalam kegiatan promosi pada motor Yamaha Tjahaja Baru menggunakan teknologi Augmented Reality berbasis android. Nantinya penelitian ini akan memunculkan objek 3D dari motor pada brosur sehingga brosur menjadi lebih menarik dan mampu menampilkan visualisasi dari bentuk motor secara lebih nyata. Aplikasi ini membutuhkan marker berupa brosur dari Yamaha sehingga ketika marker di deteksi oleh aplikasi akan memunculkan objek 3D dari motor sehingga konsumen dapat melihat desain dari motor secara lebih jelas. Hasil dari penelitian ini adalah aplikasi Augmented Reality berbasis android yang akan menampilkan desain 3D dari motor, mengganti variasi motor dan mampu menampilkan informasi dari masing-masing motor. Dengan demikian aplikasi ini dapat meningkatkan daya tarik konsumen dalam kegiatan promosi di Yamaha Tjahaja Baru. Keywords: Augmented Reality, Marker, Android, 3D, Motor, Yamaha
\end{abstract}

\section{PENDAHULUAN}

Augemented Reality merupakan teknologi yang menggabungkan benda maya dua dimensi ataupun tiga dimensi ke dalam sebuah lingkungan nyata tiga dimensi lalu memproyeksikan benda-benda tersebut secara real time. Sistem dalam augmented reality bekerja dengan menganalisa secara real time objek yang di tangkap dalam kamera. [1]

Augmented Reality memiliki kelebihan dalam pengembangan lebih mudah dan murah, kelebihan lain dari AR yaitu dapat di implementasikan secara luas dalam berbagai media. Sebagai aplikasi dalam sebuah smartphone, dalam bingkisan sebuah produk bahkan media cetak seperti buku, majalah, atau koran. Dalam kelebihan tersebut, augmented reality memiliki banyak peluang untuk terus dikembangkan salah satunya dalam bidang promosi berbisnis brosur.

Masalah yang terjadi selama ini di tempat penjualan motor adalah ketika konsumen yang ingin membeli atau melihat terlebih dahulu motor yang akan di beli tetapi motor tersebut tidak tersedia di tempat penjualan maka sebagai alternatifnya menggunakan brosur untuk memberikan informasi visual terhadap motor yang akan dibeli.

Pada saat ini tampilan yang terdapat pada brosur masih menggunakan tampilan biasa yang terdapat pada majalah lainnya, disini penulis ingin melakukan perubahan sistem dimana pada awalnya sistem yang digunakan menggunakan gambar 2D yang hanya dapat dilihat dari satu sudut saja menjadi gambar 3D yang dapat menampilan detail dari bentuk motor dengan bantuan smartphone android.

\section{LANDASAN TEORI}

\subsection{Rekayasa Perangkat Lunak}

Rekayasa perangkat lunak (software enginering) merupakan pembangunan dengan menggunakan prinsip atau konsep rekayasa dengan tujuan menghasilkan perangkat lunak yang bernilai ekonomi yang dipercaya dan bekerja scara efisien menggunakan mesin[2].

\subsection{UML (Unified Modelling Langguage)}

\subsubsection{Defenisi UML}

Unified Modelling Language (UML) merupakan bahasa visual untuk pemodelan dan komunikasi mengenai sebuah sistem dengan menggunakan diagram dan teks-teks pendukung. UML 
muncul karena adanya kebutuhan pemodelan visual untuk menspesifikasikan, menggambarkan, membangun dan mendokumentasikan dari sistem perangkat lunak. [2]

\section{Use Case Diagram}

Pada jurnal ini hanya akan dibahas 7 buah diagram UML.[2]

Use Case atau use case diagram merupakan pemodelan untuk kelakuan (behavior) sistem informasi yang akan dibuat. Use case mendiskripsikan sebuah interaksi antara satu atau lebih aktor dengan sistem informasi yang akan dibuat. Use case digunakan untuk mengetahui fungsi apa saja yang ada didalam sebuah sistem informasi dan siapa saja yang berhak menggunakan fungsi-fungsi itu.[2]

\section{Class Diagram}

Diagram Aktivitas atau Activity diagram menggambarkan workflow (aliran kerja) atau aktifitas dari sebuah sistem atau proses bisnis atau menu yang ada pada perangkat lunak. Yang perlu diperhatikan disini adalah bahwa diagram aktvitas mengambarkan aktivitas sistem bukan apa yang dilakukan aktor, jadi aktivitas yang dapat dilakukan oleh sistem.[2]

\section{Sequence Diagram}

Diagram Sequence mengambarkan kelakuan objek pada use case dengan mendiskripsikan waktu hidup objek dan message yang dikirmkan dan diterima antar objek. Oleh karena itu untuk mengambarkan diagram sekuen maka harus diketahui objek - objek yang terlibat dalam sebuah use case beserta metode - metode yang dimiliki kelas yang diinstansiasi menjadi objek itu. Membuat diagram sekuen juga dibutuhkan untuk melihat skenario yang ada pada use case.[2]

\section{Collaboration Diagram}

Collaboration Diagram mengambarkan interaksi antar objek/bagian dalam bentuk urutan pengiriman pesan. Collaboration diagram merepresentasikan informasi yang diperoleh dari diagram kelas, diagram sekuen, dan diagram use case untuk mendiskripsikan gabungan antara struktur statis dan tingkah laku dinamis dari suatu sistem. Collaboration diagram adalah bentuk lain dari sequence diagram. Bila sequence diagram diorganisir menurut waktu maka collaboration diagram diorganisir menurut ruang dan waktu. [2]

\section{Statechart Diagram}

Statechart Machine Diagram atau statechart diagram atau disebut diagram mesin atau diagram status digunakan untuk menggambarkan perubahan status atau transisi status dari sebuah mesin atau sistem atau objek. Jika diagram sekuen digunakan sebagai interaksi antar objek maka diagram status digunakan sebagai interaksi di dalam sebuah objek. Perubahan tersebut digambarkan dalam suatu graf berarah. Statechart Diagram merupakan pengembangan dari diagram Finite State Automata dengan penambahan beberapa fitru dan konsep baru.[2]

\section{Activity Diagram}

Diagram Aktivitas atau Activity Diagram menggambarkan workflow (aliran kerja) atau aktifitas dari sebuah sistem atau proses bisnis atau menu yang ada pada perangkat lunak. Yang perlu diperhatikan disini adalah bahwa diagram aktvitas mengambarkan aktivitas sistem bukan apa yang dilakukan aktor, jadi aktivitas yang dapat dilakukan oleh sistem.[2]

\section{Deployment Diagram}

Deploymentphysical diagram menggambarkan detail bagaimana komponen di-deploy dalam infrastruktur sistem, di mana komponen akan terletak (pada mesin, server atau piranti keras apa), bagaimana kemampuan jaringan pada lokasi tersebut, spesifikasi server, dan hal-hal lain yang bersifat fisikal Sebuah node adalah server, workstation, atau piranti keras lain yang digunakan untuk men-deploy komponen dalam lingkungan sebenarnya. [2]

\subsection{Augmented Reality}

Augemented Reality merupakan teknologi yang menggabungkan benda maya dua dimensi ataupun tiga dimensi ke dalam sebuah lingkungan nyata tiga dimensi lalu memproyeksikan benda-benda tersebut secara real time. Sistem dalam augmented reality bekerja dengan menganalisa secara real time objek yang di tangkap dalam kamera.[1] 
Augmented Reality adalah tekonologi yang memungkinkan orang untuk memvisualisasikan dunia maya sebai bagian dari dunia nyata yang ada di sekitar secara efektif sehingga membuat dunia nyata seakan-akan dapat terhubung dengan dunia maya dan dapat terjadi suatu interaksi.[3]

\subsection{Android}

Android merupakan subset perangkat lunak untuk perangkat mobile yang meliputi sistem operasi, middleware, dan aplikasi inti yang dirilis oleh Google. Android adalah sistem operasi bergerak (mobile operating system) yang mengadopsi sistem operasi linux, namun telah dimodifikasi.[4]

Android adalah sistem operasi untuk telepon seluler yang berbasis Linux. Android menyediakan platform terbuka bagi para pengembang untuk menciptakan aplikasi mereka sendiri untuk digunakan oleh bermacam piranti bergerak.[5]

Android adalah sebuah sistem operasi untuk perangkat mobile berbasis linux yang mencakup sistem operasi, middleware dan aplikasi. Android menyediakan platform terbuka bagi para pengembang untuk menciptakan aplikasi mereka.[6]

\subsection{Brosur}

Brosur adalah media informasi yang berisi yang berisi pesan lengkap tentang suatu hal yang ingin disampaikan, sebagai bahan penyuluhan. Isi informasi dapat dalam bentuk kalimat maupun gambar atau kombinasi.[7]

Brosur merupakan salah satu media informatif yang terdiri dari satu atau beberapa halaman yang digunakan oleh banyak orang untuk promosi dan pengenalan, baik itu produk ataupun jasa. Brosur bersifat tidak berkala dan terbitnya selesai dalam sekali terbit. Di mana-mana sering terlihat orang membagikan brosur entah itu di jalan, pertokoan atau institusi kita bisa dengan mudah mendapatkan brosurnya. Dalam brosur biasanya dimuat informasi atau penjelasan tentang produk, jasa atau profil yang jelas tapi ringkas dan menarik untuk membangun citra yang baik dari perusahaan atau institusi tersebut. Walaupun kelihatannya bersifat tradisional, namun kenyataannya menggunakan brosur sebagai media promosi dan pengenalan juga cukup efektif dalam menarik perhatian masyarakat umum.[8]

\subsection{Promosi}

Promosi merupakan insentif jangka pendek dalam aktifitas promosi untuk meransang pembelian suatu produk dengan cara yang bervariasi, seperti pameran dagang, insentif penjualan, kupon dan sebagainya.[9]

Promosi mengacu pada setiap insentif yang digunakan oleh produsen untuk memicu transaksi (pedagang besar dan ritel) dan/atau konsumen untukmembeli suatu merek serta mendorong tenaga penjualan untuk secara agresif menjualnya. Dengan kegiatan promosi yang dilakukan, perusahaan akan berusaha untuk membujuk calon pembeli dan langganan untuk melakukan pembelian atas produk yang dipasarkan, dalam hal ini perusahaan melakukan komunikasi dengan konsumen.[10]

\section{ANALISA PROSES}

\subsection{Analisa Data}

Analisa data dapat didefinisikan sebagai salah satu cara untuk mengolah data menjadi informasi, sehingga karakteristik data tersebut dapat dipahami dan bermanfaat untuk menyelesaikan suatu masalah.

Pada tahap ini data diperoleh dari Showroom Yamaha Tjahaja Baru mengenai jenis-jenis dari motor yamaha dan brosur dari motor yamaha Tjahaja Baru. Data tersebut berupa gambaran dari motor yang ada pada Yamaha Tjahaja Baru.

\subsection{Analisa Sistem}

Pada tahap ini dilakukan pengumpulan materi data-data tentang motor yang ada di showroom Yamaha Tjahaja Baru tersebut, desain 3D dan augmented reality. Kemudian membuat desain 3D dari motor dan menerapkannya pada augmented reality berbasis android.

Pada tahap ini analisa aplikasi augmented reality sebagai media memvisualisasikan bentuk dari motor pada Yamaha Tjahaja Baru agar lebih menarik dengan menggunakan marker berbasis android. Hasil analisa tersebut digunakan untuk merancang perangkat lunak. Analisa perangkat lunak merupakan langkah pemahaman persoalan sebelum mengambil tindakan atau membuat rincian sistem hasil dari analisa menjadi bentuk perancangan agar dimengerti oleh penguna. 
Analisa perangkat lunak merupakan langkah pemahaman persoalan sebelum mengambil tindakan atau membuat rincian system hasil dari analisa menjadi bentuk perancangan agar dimengerti oleh pengguna.

\subsection{Perangcangan Model}

Aplikasi ini dirancang menggunakan alat bantu berupa UML (Unified Modelling Langguage) agar mempermudah memindahkan konsep sistem yang dirancang ke dalam bentuk program, dimana perancangannya digambarkan dalam bentuk diagram berikut :

\section{Use Case Diagram}

Diagram use case yang ditampilkan bertujuan untuk menjelaskan apa saya yang bisa dilakukan oleh aktor-aktor yang dapat mengoperasikan sistem. Untuk melihat apa saja yang bisa dilakukan oleh aktor dapat dilihat pada tampilan gambar 1 berikut :

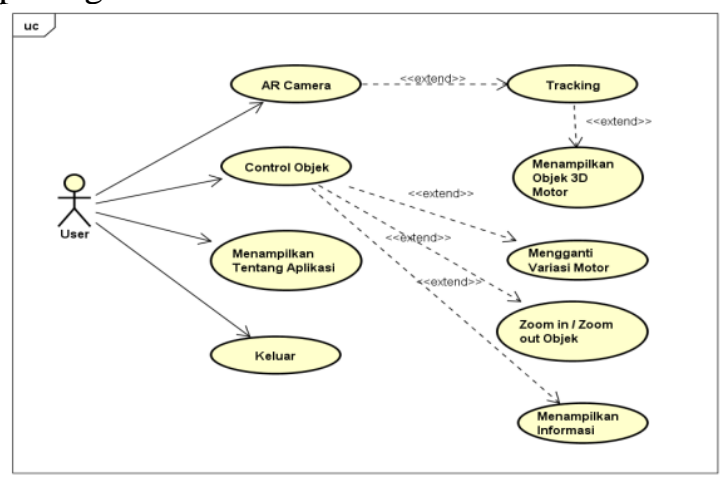

\section{Class Diagram}

\section{Gambar 1 Use Case Diagram}

Class Diagram adalah model statis yang menggambarkan struktur dan deskripsi class serta hubungannya antara class.

Dan berikut ini merupakan gambaran dari class diagram :

\section{Activity Diagram}

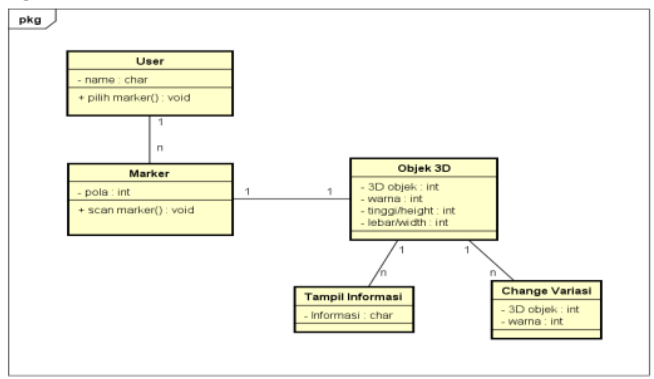

\section{Gambar 2Class Diagram}

Activity diagram menggambarkan berbagai alir aktivitas dalam sistem yang sedang dirancang, bagaimana masing-masing alir berawal, decision yang mungkin terjadi, dan bagaimana mereka berakhir. 


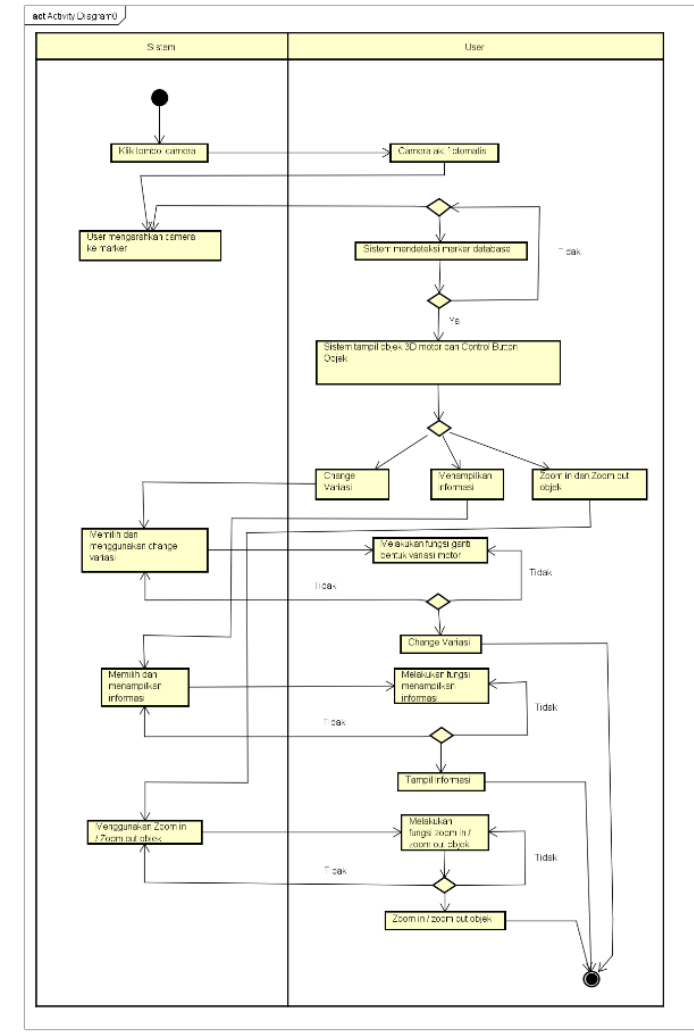

\section{State Chart Diagram}

Gambar 3 Activity Diagram

Statechart diagram menggambarkan transisi dan perubahan keadaan (dari satu state ke state lainnya) suatu objek pada system. Pada umumnya statechar diagram menggambarkan class tertentu.

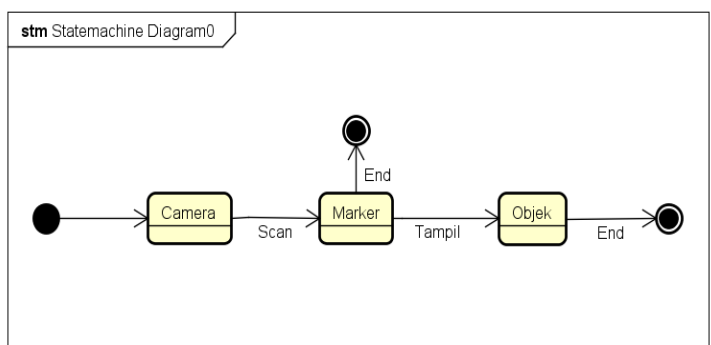

\section{Gambar 4 Statechart DiagramMenampilkan Objek}

\section{Sequence Diagram}

Sebuah sequence diagram, secara khusus, menjabarkan behavior sebuah scenario tunggal. Diagram tersebut menunjukkan sejumlah objek contoh dan pesan-pesan yang melewati objek-objek didalam use case. Squence diagram menggambarkan interaksi antar objek di dalam dan disekitar sistem (termasuk user, display, dan sebagainya) berupa message yang digambarkan terhadap waktu.

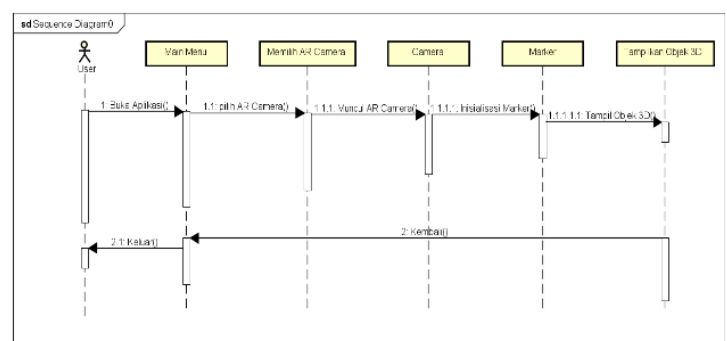

Gambar 5 Sequence Diagram Tampil Objek 


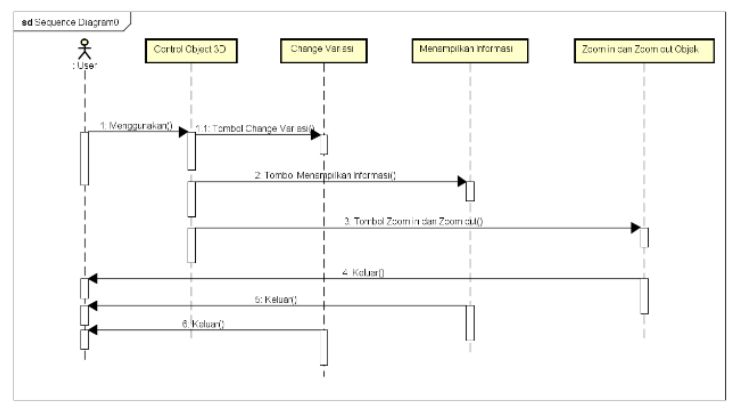

\section{Collaboration Diagram}

\section{Gambar 6 Sequence Diagram Control Objek}

Collaboration diagram menunjukkan physical view dari suatu sistem yang akan dibangun. Collaboration diagram menekankan pada urutan message (pesan) antara objek sistem. Hal ini berbeda dengan sequence diagram yang menekankan pada urutan waktu.

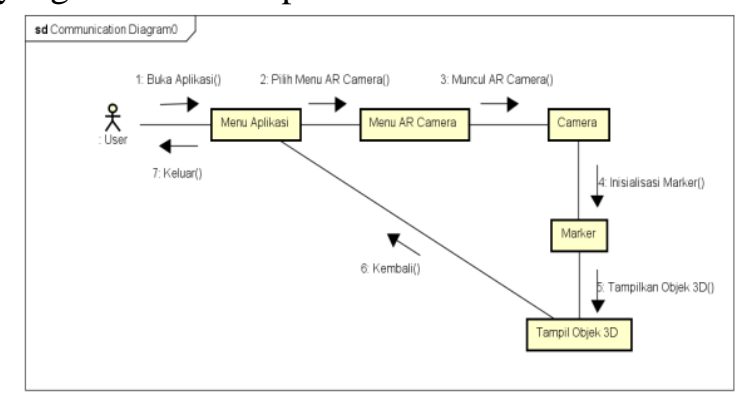

\section{Gambar 7 Collaboration diagram Tampil Objek}

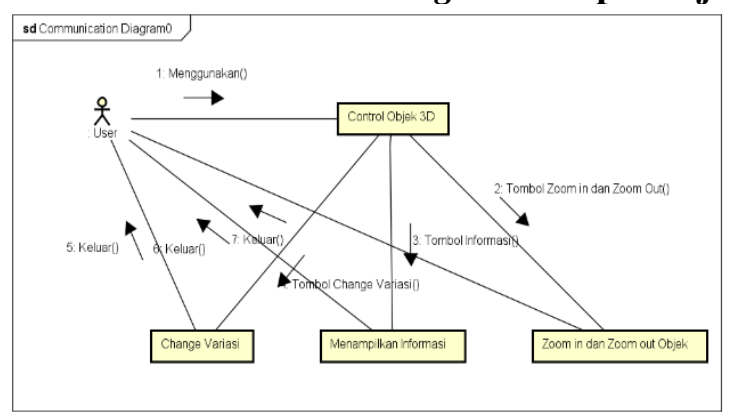

\section{Deployment Diagram}

\section{Gambar 8 Collaboration Diagram Control Objek}

Deployment diagram menggambarkan secara lengkap bagaimana komponen di deploy dalam infrastruktur sistem, dimana komponen akan terletak, bagaimana kemampuan jaringan pada kondisi tertentu, spesifikasi server, dan hal-hal lain yang bersifat fisikal. Hubungan antar node (misalnya $\mathrm{TCP} / \mathrm{IP}$ ) requiretment dapat juga didefenisikan dalam diagram ini.

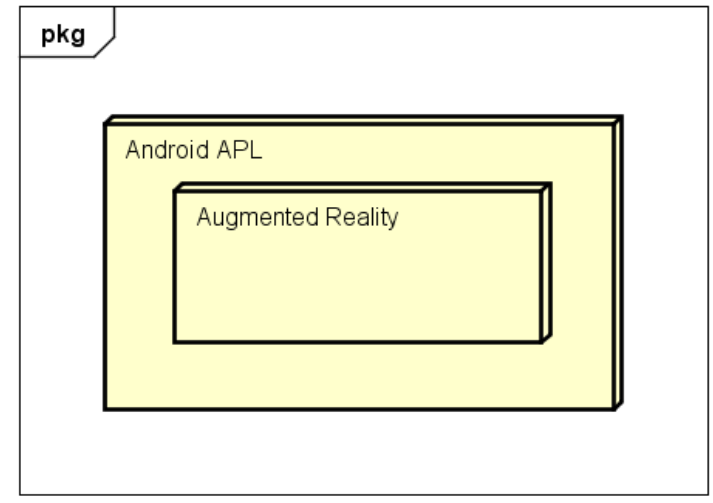

Gambar 9 Deployment Diagram 


\section{IMPLEMENTASI SISTEM}

Implementasi sistem merupakan tahapan dalam pengembangan sistem, untuk melakukan sebuah implementasi maka diperlukan perancangan interface guna untuk interaksi antara user dengan sistem dan penulisan kode program yang sesuai dengan kebutuhan sistem aplikasi yang dirancang.

\subsection{Pengujian Interface}

Pengujuan interface adalah tahapan untuk merancang halaman website yang akan dibuat deangan aplikasi App server yang telah diinstal, berikut adalah halaman tampilan website yang telah dirancang.

\subsubsection{Halaman Utama}

Pada halaman akan ditampilkan main menu.

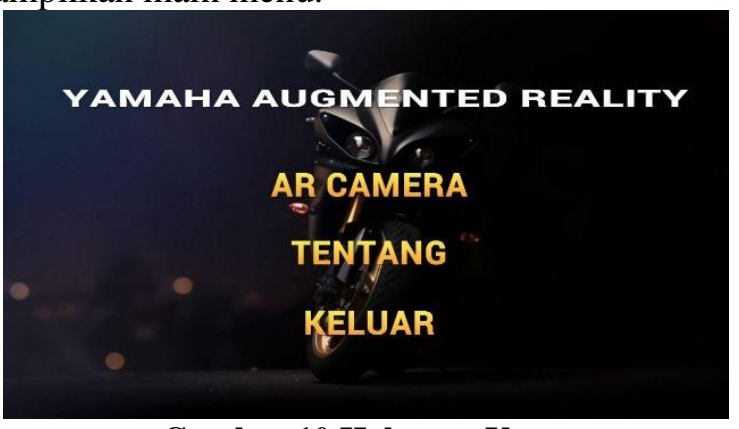

\subsubsection{Halaman AR Camera}

Gambar 10 Halaman Utama

Berikut adalah tampilanmenu AR Camera:

\subsubsection{Halaman Tentang}

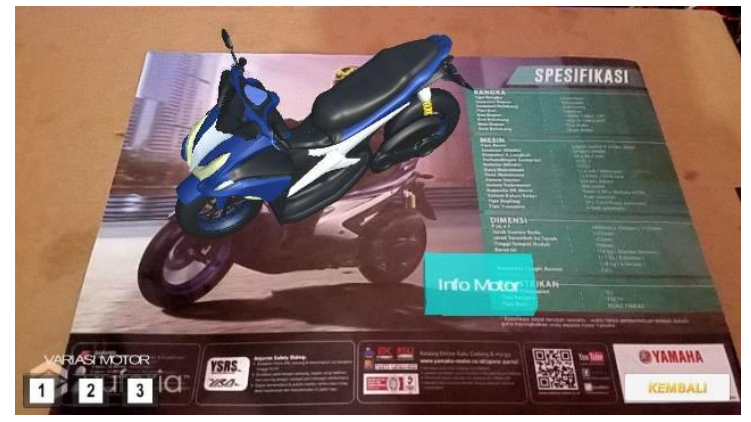

Gambar 11 Halaman AR Camera

Berikut adalah tampilan menutentang.

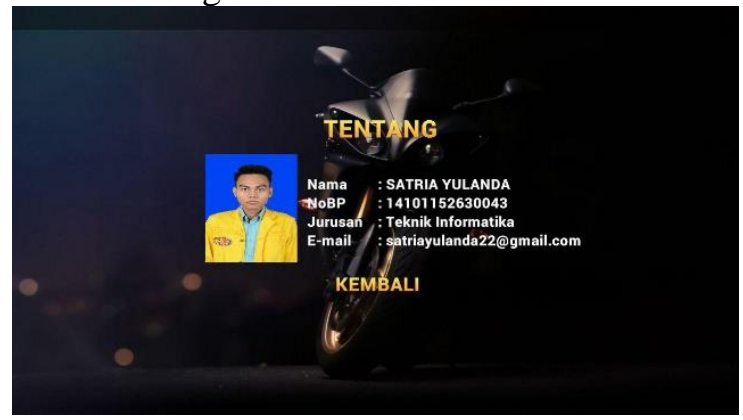

Gambar 12 Halaman Tentang

\section{KESIMPULAN}

Dari pembuatan aplikasi Yamaha AR maka dapat disimpulkan bahwa:

1. Aplikasi Augmented Reality ini dapat menjadi sarana baru showroom Yamaha Tjahaja Baru dalam mempromosikan produknya dnegan menarik.

2. Dengan aplikasi Augmented Reality menggunakan objek 3D pada brosur Yamaha Tjahaja Baru yang menarik dapat menampilkan bentuk fisik dari motor secara 3D tanpa harus melihat motor secara langsung.

3. Dengan aplikasi Augmented Reality dapat menjadi media baru dalam memberikan visualisasi produk dari Yamaha kepada konsumen. 


\section{DAFTAR PUSTAKA}

[1] Rizal H, Muh,dkk. 2014. Mobile Augmented Reality Fasilitas Umum Kota Makassar Berbasis Android. Jurnal Sains dan Teknologi Universitas STMIK AKBA Makassar. Vol.3,No.1. ISSN : 2303-3614.

[2] S., Rosa dan Shalahuddin, M. 2013. Rekayasa Perangkat Lunak Terstruktur Dan Berorientasi Objek. Informatika. Bandung.

[3] Wahyutama, Febrian,dkk. 2013. Penggunaan Teknologi Augmented Reality Berbasis Barcode sebagai Sarana Penyampaian Informasi Spesifikasi dan Harga Barang yang Interaktif Berbasis Android. Jurnal Teknik POMITS. Vol.2,No.3. ISSN : 2337-3539.

[4] Nugraha Lengkong, Hendra,dkk. 2015. Perancangan Penunjuk Rute Pada Kendaraan Pribadi Menggunakan Aplikasi Mobile GIS Berbasis Android Yang Terintegrasi Pada Google Maps. Jurnal Teknik Elektro dan Komputer Universitas UNSRAT Manado. ISSN : 2301-8402

[5] Sulihati dan Andriyani. 2016. Aplikasi Akademik Online Berbasis Mobile Android Pada Universitas Tama Jagakarsa. Jurnal Sains dan Teknologi Utama. Vol.11,No.1. ISSN : 1978001X

[6] Maulindar, Joni,dkk. 2016. Perancangan Aplikasi Tagihan Spp Berbasis Android. Jurnal Sains Tech Politeknik Indonusa Surakarta. Vol.1,No.5. ISSN : 2355-5009.

[7] Stefanie, Ruth. 2013. Respon Pengunjung Terhadap Media Brosur Jatim Park 2. Jurnal EKomunikasi Universitas Kristen Surabaya. Vol.1.No.3.

[8] M. Lengkey, Debora,dkk. Brosur Fakultas Teknik Universitas Sam Ratulangi Manado Dengan Teknologi Markerless Augmented Reality. Jurnal Teknik Elektro dan Komputer Universitas UNSRAT Manado. ISSN : 2301-8402.

[9] Nurul Faroh, Wahyu. 2017. Analisa Pengaruh Harga, Promosi, Dan Pelayanan Terhadap Keputusan Pembelian. Jurnal Ilmiah Universitas Pamulang. Vol.4,No.2.

[10] Rokhmi Fuadati, Tria. 2014. Pengaruh Strategi Promosi Terhadap Penjualan Produk Di PT. UNITED INDO SURABAYA. Jurnal Ekonomi STIESIA Surabaya. Vol.3,No.10. 